Rev. Roum. Chim.,
ACADEMIA ROMÂNĂ
Revue Roumaine de Chimie
http://web.icf.ro/rrch/

\title{
ELECTROCATALYTIC ACTIVITY SURVEY OF SOME CATHODE MATERIALS FOR THE REDUCTION OF NITRITES AND NITRATES IN AQUEOUS SOLUTION
}

\author{
Yassmina ANGAR, ${ }^{\mathrm{a}^{*}}$ Sofiane DAOUDI, ${ }^{\mathrm{b}}$ Salima KEBBOUCHE-GANA ${ }^{\mathrm{c}}$ and Nacer-Eddine DJELALI ${ }^{\mathrm{a}}$ \\ ${ }^{a}$ Laboratory of treatment and formatting of polymers, Faculty of engineering sciences, University of M'Hamed Bougara, \\ Boumerdes 35000, Algeria \\ ${ }^{\mathrm{b}}$ Chemistry department, Faculty of Sciences, University of M'Hamed Bougara, Boumerdes 35000, Algeria \\ ${ }^{c}$ Laboratory of VALCOR, Faculty of sciences, University of M'Hamed Bougara, Boumerdes 35000, Algeria
}

Received August 27, 2020

\begin{abstract}
The electrochemical techniques are the subject of increasing interest on the environmental remediation methods thanks to their efficiency and their selectivity. It was classified among the cleanest methods because it does not produce sludge and undesirable intermediate byproducts. For these reasons, we have chosen this technology for the reduction of nitrites and nitrates ions from aqueous solutions. The objective of our study is the comparison of several cathodes materials performances, in order to promote an optimal electroreduction of these ions. Indeed, we have used the copper, graphite, stainless steel and zinc as cathodes; among them, we have selected the most efficient on which we have optimized the operational conditions. The results suggested that the copper cathode was the most efficient for the reduction of both tested ions compared to the other tested materials. Therefore, the optimization of operational conditions allows us to fixed them at: scan rate $=50 \mathrm{mV} / \mathrm{s}$, initial effluent concentration $=100 \mathrm{mg} / \mathrm{L}, \mathrm{pH}=7$ and potential range of the cyclic voltammetry scanning of $[-1,+1] \mathrm{V} / \mathrm{SCE}$ for both ions. Under these optimal parameters, the reduction yield after $45 \mathrm{~min}$ was important that can achieve $96.5 \%$ and $99 \%$ for nitrites and nitrates respectively.
\end{abstract}

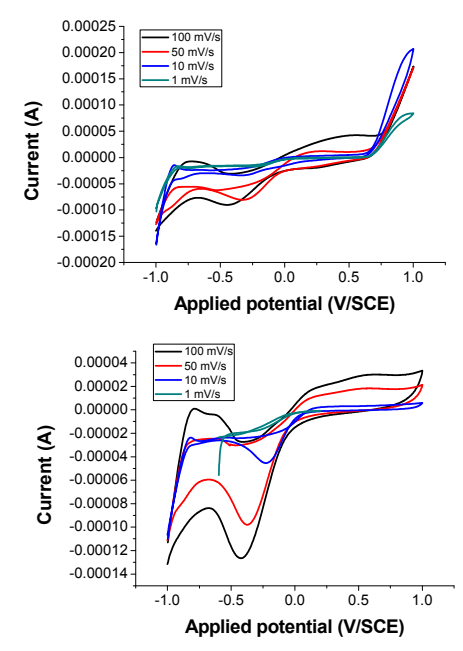

\section{INTRODUCTION}

Nitrites and nitrates are considered as essential nutrients for the growth of plants and certain microorganisms. However, the excessive use of these nitrogen forms as fertilizers leads to the imbalance of the nitrogen cycle and thus conduct to several pollution problems by; their accumulation in the soil as organic and mineral matters and consequently the pollution of the water reservoirs because of the high solubility of nitrites and nitrates in cold water. ${ }^{1,2}$ Moreover, some studies have shown that $10 \%$ of this pollution is attributed to industrial activities including; food industry that used nitrites as antimicrobial agents, heavy industry that generate these pollutions during various processes, pharmaceutical industry that made these oxide nitrogen during the synthesis of certain drugs. ${ }^{3,4}$ The water pollution by these matters conduct to the development of eutrophication phenomena that leads to asphyxiation and consequently the disappearance of certain aquatic species by default of oxygen and light. ${ }^{4}$ Furthermore, the nitrate could be transformed to

\footnotetext{
*Corresponding author: y.angar@univ-boumerdes.dz
} 
nitrites by bacteria that are naturally present in the digestive system, the formed nitrites can cause methemoglobinemia malady. ${ }^{5}$

Indeed, researches have been devoted to combat the exponential propagation of nitrite and nitrate in water and also in soil. Over the past four decades, science has opened several doors to treat this pollution in biology by dentrifications reactions (heterotrophic, ${ }^{6-8}$ autotrophic ${ }^{9-11}$ and physicochemistry by application of several techniques such as; ionic exchange, ${ }^{12-14}$ membrane treatment, ${ }^{15}$ nanofiltration ${ }^{16}$ and other). Thus, each method has their advantages and disadvantages depending of their effectiveness and their environmental consequences. So, some treatment methods can only move the pollution from the aquatic environment to another medium. Other methods can lead to the production of undesirable byproducts that require further processing.

Among the nitrate and nitrite treatment methods, the electrochemical techniques are known as the cleanest advanced treatment, it used to remove nitrites and nitrates and several other pollutants from the electrolytic medium by oxidation or reduction without producing sludge or toxic byproducts. ${ }^{17-19}$

The electrochemical reduction of nitrate ions at the cathode surface could gave various products, such as nitrites, ammonia or nitrogen gas depending to the applied potential, the reaction mechanisms of these reductions are presented in the following equations (1)-(3). ${ }^{18,20-22}$

$$
\begin{aligned}
& \mathrm{NO}_{3}^{-}+\mathrm{H}_{2} \mathrm{O}+2 \theta^{-} \leftrightarrow \mathrm{NO}_{2}^{-}+2 \mathrm{~K}^{-} \mathrm{H} \\
& \mathrm{NO}_{\mathrm{g}}^{-}+3 \mathrm{H}_{2} \mathrm{O}+5 \theta^{-} \leftrightarrow \frac{1}{2} \mathrm{~N}_{2}+60 \mathrm{H}^{-} \ldots \ldots \ldots E^{0}=0.26 \mathrm{~V} / \mathrm{ENH} \\
& \mathrm{NO}_{\mathrm{g}}^{-}+6 \mathrm{H}_{2} \mathrm{O}+8 e^{-} \leftrightarrow \mathrm{NH}_{\mathrm{g}}+90 \mathrm{H}^{-} \mathrm{HE} \ldots \mathrm{E}^{\circ}=-0.12 \mathrm{~V} / \mathrm{ENH}
\end{aligned}
$$

In the other hand, the principal cathodic reactions of the electrochemical reduction of nitrites ions depending of the applied potential are shown in the equations (4) and (5).

$$
\begin{aligned}
& \mathrm{NO}_{2}^{-}+2 \mathrm{H}_{2} \mathrm{O}+3 \mathrm{e}^{-} \leftrightarrow \frac{1}{2} \mathrm{~N}_{2}+4 \mathrm{OH}-\mathrm{H} \ldots \mathrm{H} \mathrm{E}^{\circ}=0.406 \mathrm{~V}^{\mathrm{V}} / \mathrm{ENH} \\
& \mathrm{NO}_{2}^{-}+5 \mathrm{H}_{2} \mathrm{O}+6 e^{-} \leftrightarrow \mathrm{NH}_{\mathrm{g}}+70 \mathrm{H}^{-} \mathrm{n} \ldots \mathrm{E} \mathrm{E}^{0}=-0.165 \mathrm{~V} / \mathrm{EWH}
\end{aligned}
$$

Moreover, the elimination of nitrite could be effectuated by indirect chemical reaction in the presence of the chloride in the medium according to the following mechanism. ${ }^{20-22}$

$$
\begin{gathered}
2 \mathrm{Cl}^{-} \rightarrow \mathrm{Cl}_{2}+2 \theta^{-} \\
\mathrm{Cl}_{2}+\mathrm{H}_{2} \mathrm{O}+\mathrm{HClO}+\mathrm{H}^{+}+\mathrm{Cl}^{-} \\
\mathrm{HOCl} \rightarrow \mathrm{OCl}^{-}+\mathrm{H}^{+} \\
\mathrm{NO}_{2}^{-}+\mathrm{OCl}^{-} \rightarrow \mathrm{NO}_{3}^{-}+\mathrm{Cl}^{-}
\end{gathered}
$$

Nitrites ions are chemically oxidized to nitrates by the intermediate of hypochlorite ion (eq. 9), the produced nitrate transforms to atmospheric nitrogen according the eqs. (1), (2) and (3).

Therefore, researches have focused on studying of the activity and the selectivity of cathode materials for the reduction of nitrates and nitrites. Thus, the most effective materials for this treatment are the noble metals such as; platinum, ${ }^{23}$ lead, ${ }^{24}$ nickel. ${ }^{25,26}$ Moreover, certain transition metals have presented an important activity for these reductions such as; copper ${ }^{27,28}$ and their alloys with palladium (Pd-Cu) ${ }^{27,29,30}$ some of which are very active in acidic medium.
In the present work, we have elaborated four materials of copper, graphite, stainless steel and zinc as cathodes, in order to evaluate their electrocatalytic effectiveness for the electrochemical reduction of nitrates and nitrites in aqueous solution.

The selection of these materials is related to their availability, electroactivity, non passivity in the nitrites and nitrates reduction ranges and their effectiveness without production of harmful products. The use of our selected materials is beneficial compared to that studied in previous researches, such as; noble metals ${ }^{23,26}$ and alloys ${ }^{27,29}$ that required a post fabrication, several chemical reagents for their treatments and the high costs of the raw materials.

We have compared the performance of each material to select the best one among them that gave significant reductions of both ions; nitrate and nitrite. Using this cathode, we have studied the effect of the operating conditions on the reaction in order to provide a favorable reaction medium for a significant electro-reduction of the desired ions. 


\section{MATERIALS AND METHODS}

\section{Reagents and solutions}

The reagents used in this work are; Sodium nitrate $\left(\mathrm{NaNO}_{3}\right)$, sodium nitrite $\left(\mathrm{NaNO}_{2}\right)$, Sodium hydroxide $(\mathrm{NaOH})$, sodium salicylate $\left(\mathrm{C}_{7} \mathrm{H}_{5} \mathrm{NaO}_{3}\right)$, potassium nitrate $\left(\mathrm{KNO}_{3}\right)$, potassium sodium tartrate $\left(\mathrm{C}_{4} \mathrm{H}_{4} \mathrm{KNaO}_{6}\right)$. All these reagents are solid salts with average purities of $99 \%$. Thus, the solutions of these reagents used for our manipulations were prepared by distilled water.

\section{Elaboration of the cathodes}

\section{Copper electrode}

The copper electrode used in this work is a plate lamina with dimensions of $6 \mathrm{~cm} \times 2 \mathrm{~cm}$ and a thickness of $1 \mathrm{~mm}$. So, we have limited the active surface of this lamina at $4.4 \times 2 \mathrm{~cm}^{2}$, this surface are polished manually by abrasive papers of increasing grit sizes of $120 ; 220$ and 400 in order to eliminate large scratches to obtain uniform surface. After that, the active surface of copper electrode is polished in the polishing machine using different abrasive papers started by 600,800 and then 1200 during $5 \mathrm{~min}$ of each one with a rotator speed of 500 RPM under a continuous water flow. Subsequently, we plunged the polished electrode into an acetone solution for $30 \mathrm{~min}$ to remove any organic matter that may be present on the surface. Finally, the electrode was polished once again by sandpaper of 1200 and rinsed with distilled water.

\section{Zinc, graphite and stainless steel electrodes}

These three materials have not a uniform surface, for this reason they have been reformed in order to obtain easily usable electrodes with a welldefined active surface area. So, we have attached the materials by a current-conducting wire to connect it to the potentiostat. In the other hand, we have prepared the epoxy resin to isolate the unwanted surfaces of the electrodes. In addition, we covered the electric cable with a plastic pipe to prevent any contact with the electrolytic solution. Then we have put our electrode in a mold previously lubricated with Vaseline to facilitate the electrode demoulding, and we have introduced the resin in the mold all around the electrode to cover the sides. The resin was dried in the open area for 12 hours until the solidification of the resin and the easily demoulded of the electrodes.

The obtained electrodes had irregular contact surfaces, which require several polishing in order to eliminate exceed resin and to uniform the active area. For that, the electrodes were firstly manually polished by abrasive paper of 120 and 220, and then by polishing machine using different abrasive papers started by 600,800 and then 1200 during $5 \mathrm{~min}$ for each one with a rotator speed of 500 RPM under a continuous water flow to obtain very smooth and homogeneous electrode surfaces. The electrodes were immersed in acetone solution for $30 \mathrm{~min}$ and polished once again by sandpaper of 1200 and then rinsed with distilled water. The characteristics of these electrodes are presented in the following table (Table 1).

\section{Construction of the electrochemical chain}

Electrochemical cell used in this study is a double wall Pyrex glass with a capacity of $100 \mathrm{ml}$, equipped with a lid that contains three necks. For the anode, we used platinum as anode of the oxidation reactions, and the saturated calomel electrode as reference electrode.

The electrodes are connected to the potentiostat and the resulting graphs are executed on a computer recorder, which is connected to the potentiostat. All electrochemical experiments were performed at open air.

\section{Study of operating conditions effect on the nitrite and nitrate reduction}

This study was carried out on a cell containing $100 \mathrm{~mL}$ of the contaminated solution (with nitrites or nitrates) at a concentration of $100 \mathrm{mg} / \mathrm{l}$ using cyclic voltammetric technique.

Table 1

Characteristics of tested counter electrodes

\begin{tabular}{ccc}
\hline & Base area $\left(\mathbf{c m}^{2}\right)$ & Weight $\mathbf{( g )}$ \\
\hline Zinc & 0.635 & 65,4 \\
Graphite & 0.811 & 18.48 \\
Stainless steel & 0,785 & 17,33 \\
\hline
\end{tabular}


The scanning range of voltammetry was optimized in order to delimit the range of scanning potential, for this reason we have scanned the potential of the cyclic voltammetry in the interval of $-2 \mathrm{~V}$ to a high potential of $+2 \mathrm{~V}$ returned to a started value of $-2 \mathrm{~V} / \mathrm{SCE}$ for the copper cathode.

Therefore, for the scan rate effect study, at the delimitated scanning range, different scan rate were considered $(1,10,50$ and $100 \mathrm{mV} / \mathrm{s})$.

Moreover, we tested four cathode materials to select the best among them for the optimal reduction of the desired ions. Under the optimal scan rate and scanning range the electrodes of copper, zinc, stainless steel and graphite were tested for these reductions reactions.

For the effluent concentration effect study, the previous parameter were maintained at their optimal values with different concentrations of the contaminated solutions $(10 \mathrm{mg} / \mathrm{L}, 50 \mathrm{mg} \mathrm{L}$, $100 \mathrm{mg} / \mathrm{L}, 200 \mathrm{mg} / \mathrm{L}, 300 \mathrm{mg} / \mathrm{L})$ respectively. The $\mathrm{pH}$ is an important factor in the equilibrium of the reactions. The $\mathrm{pH}$ of the contaminated solution were changed at different levels starting with acid solutions ( 3 and 5), neutral solutions $\mathrm{pH}=7$ and alkaline solutions (9 and 11).

After selecting the best cathode materials for both solutions and optimal values of initial concentration and $\mathrm{pH}$, multi-cycle voltammetric tests of: 10, 30, 60 and 100 were applied during well-defined times at optimal potential range and scan rate.

The residual nitrates concentrations were determined after each multi cycle by SHIMADZU UV-1800 spectrophotometer, and the residual nitrite concentrations was determined by a LANGE DR-1900 kit spectrophotometer using prepared reagent kits. The reduction percentages were calculated by the following equation (eq. 10)

$$
\%=\frac{q_{i}-c_{f}}{c_{f}} \times 100 \%
$$

where; $C_{i}$ is the initial concentration and $C_{f}$ is the final concentration.

\section{RESULTS AND DISCUSSION}

\section{Cathodes preparation}

The obtained cathodes of zinc, stainless steel and graphite, were covered by $1 \mathrm{~cm}$ thick layer of the resin which serves to isolate the electrical wires and to delimit the active surface area (as shown in
Fig. 1A, B and C). For the copper electrode that had a rectangular shape of double facet (Fig. $1 \mathrm{D}$ and E), we didn't covered them by the resin, it was impregnated in half in the electrolytic solution and their upper part was connected with an electric cable, which was connected to the electrical chain.

The cathodes were polished and rinsed after each assay to eliminate any products and intermediate products that could issue from the reduction.

\section{Optimization of the potential range}

We have effectuated the optimization of the applied potential range before the study of the other operating parameters effect, in order to delimit the applied potentials range and to avoid the parasitic reactions. Therefore, we have proceeded by blank test that we have used distilled water as electrolytic solution using the copper electrode as cathode. After that, we have tested two contaminated solution by $100 \mathrm{mg} / \mathrm{L}$ of nitrites and nitrates respectively. For these tests, the potential sweep of the cyclic voltammetry was fixed between -2 to $+2 \mathrm{~V} / \mathrm{SCE}$ with a scan rate of 100 $\mathrm{mV} / \mathrm{s}$. The resulting voltammograms are shown in Fig. 2.

According to the Fig. 3C, we noticed that the nitrate reduction peak is located between the potential range of $-1 \mathrm{~V} / \mathrm{SCE}$ to $+1 \mathrm{~V} / \mathrm{SCE}$ which is located exactly at $-0.3 \mathrm{~V} / \mathrm{SCE}$. For nitrite ions, the reduction peak is not clearly shown in the voltamogram spectrum because of their overlap with other peak that have higher intensities than nitrite reduction. So, we can see a small deviation of reduction path from 0 until $-1 \mathrm{~V} / \mathrm{SCE}$ comparing to blank voltammogram. For this reason, we have delimited the potential range at $[-1 ;+1] \mathrm{V} / \mathrm{SCE}$ for the two voltammetric reduction tests.

\section{Study of the operating conditions effect on the electrochemical reduction of nitrites and nitrates}

\section{Effect of scan rate}

The influence of scan rate has been studied for the four elaborated cathodes. The voltammograms obtained at different scan rate of the two solutions contaminated by $100 \mathrm{mg} / \mathrm{l}$ of nitrates and nitrites respectively are superimposed and shown in the Fig. 3. 
All the Figures 3A for the different tested cathodes showed the effect of different scanning rates on nitrite reduction. According to the results presented in these figures, we have noticed that the nitrite reduction peak that appeared at $-0.4 \mathrm{~V} / \mathrm{SCE}$, was almost identical at a scan rate of $50 \mathrm{mV} / \mathrm{s}$ for all the tested electrodes, except graphite cathode that haven't shown any reduction peak. However, two large oxidation peaks were noted at $-0.7 \mathrm{~V} / \mathrm{SCE}$ and $+0.1 \mathrm{~V} / \mathrm{SCE}$ with the zinc electrode at a scan rate of $10 \mathrm{mV} / \mathrm{s}$. Similarly, at the scan rate of $100 \mathrm{mV} / \mathrm{s}$ we observed an oxidation peak at $0.7 \mathrm{~V} / \mathrm{SCE}$ for all tested electrodes. These oxidation peaks were attributed to the non-voluntary oxidation of nitrites and thus conducted to the appearance of undesirable by-products in the electrolytic solution.

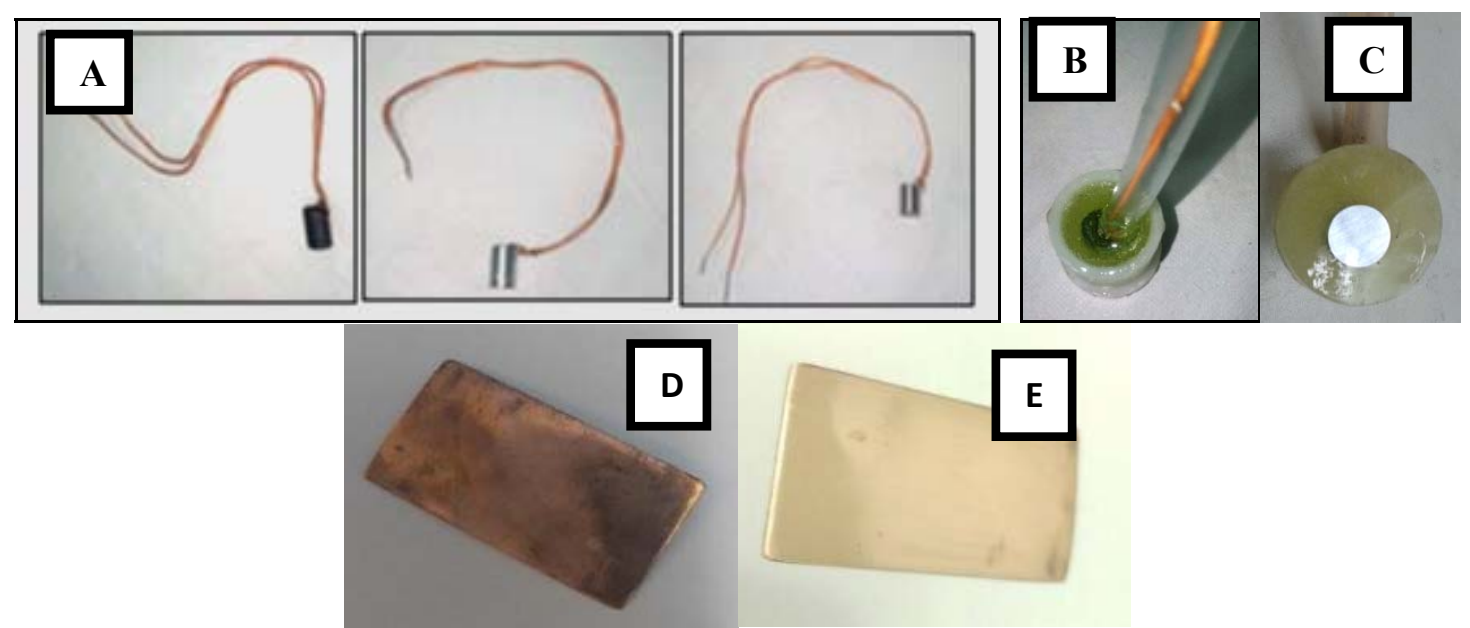

Fig. 1 - Elaboration of the cathodes of zinc, graphite and stainless steel, the first step (A), the second step (B) and the last step (C) and the Copper cathode before (D) and after (E) polishing.
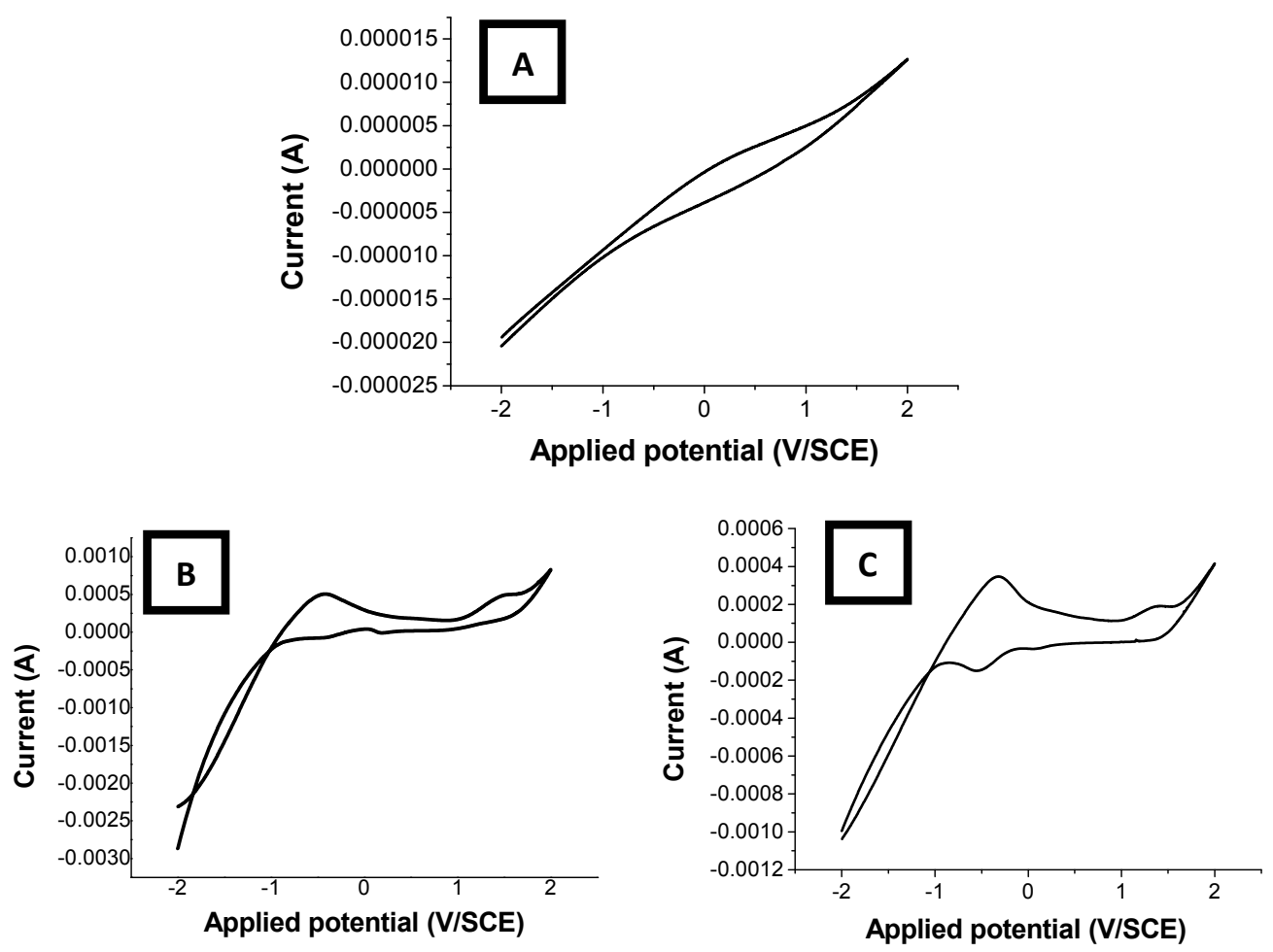

Fig. 2 - Voltammograms of the blank solution (A), nitrites (B) and nitrates (C), using copper electrode with scan rate of $100 \mathrm{mV} / \mathrm{s}$. 

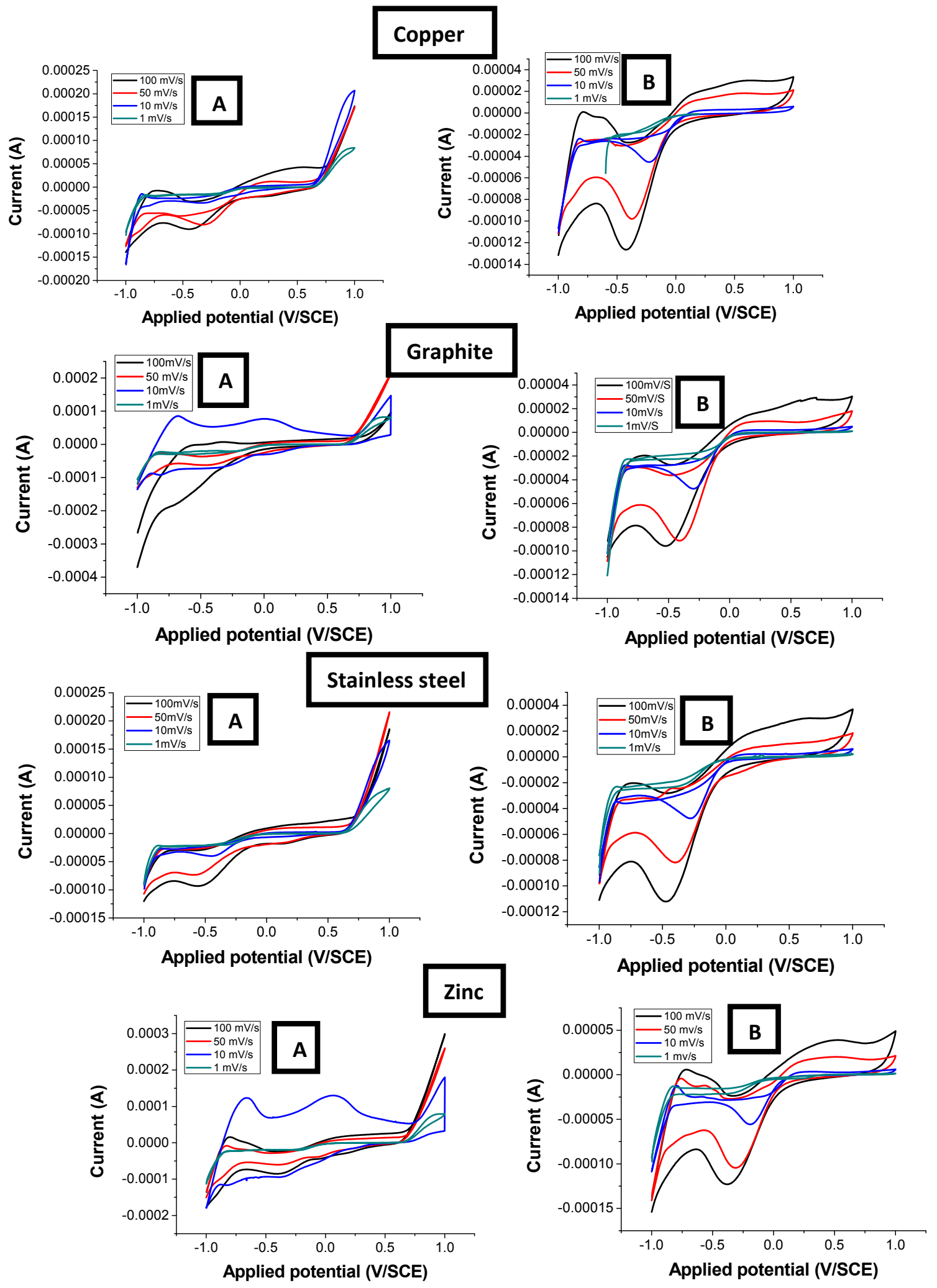

Fig. 3 - Voltammograms presented the scan rate effect on the electrochemical reduction of nitrites (A) and nitrates (B) with an initial concentration of $100 \mathrm{mg} / \mathrm{L}$ using different cathode materials (copper, graphite, stainless steel and zinc). 
Nevertheless, the reduction of nitrite could contribute to the formation of several other nitrogen forms, such as $\mathrm{NO}, \mathrm{H}_{2} \mathrm{~N}-\mathrm{OH}, \mathrm{H}_{2} \mathrm{~N}-\mathrm{NH}_{2}$ depending of the electrode materials, $\mathrm{pH}$, reduction potential, etc. like obtained in the studies of Chen et al. (2008) and Estudillo-Wong et al. (2013) $)^{31,32}$ that have used $\mathrm{Fe}$ nanoparticles and $\mathrm{Pt}$ nanoparticles respectively supported on the glass carbon electrode. The authors have obtained a release of $\mathrm{NO}$ gas at different potential $(-0.6 \mathrm{~V}$ and $-0.78 \mathrm{~V} / \mathrm{SCE}^{31}$ and $-1.18 \mathrm{~V} / \mathrm{SCE}^{32}$ ) in alkaline solution according to the following equation (eq. 11).

$$
\mathrm{NO}_{2}^{-}+\mathrm{H}_{2} \mathrm{O}+\theta^{-} \rightarrow \mathrm{NO}+2 \mathrm{OH}^{-} \ldots
$$

According to Nishimura et al. (1991), ${ }^{33}$ different volatile compounds could be produced during the $\mathrm{NO}_{2}{ }^{-}$depending to the saved potential of reduction, the authors studied the reduction of nitrite in acidic solution they found that $\mathrm{N}_{2}$ was formed at a potential range of $\mathrm{E}=0.1-0.6 \mathrm{~V} / \mathrm{NHE}$. So, the reduction of $\mathrm{NO}_{2}^{-}$to $\mathrm{N}_{2} \mathrm{O}$ took place at $\mathrm{E}=0.8-0.2 \mathrm{~V} / \mathrm{NHE}$ and the $\mathrm{NO}$ gas was produced at $\mathrm{NO}$ at $\mathrm{E}=0.6-0.1 \mathrm{~V} / \mathrm{NHE} .^{33}$

Moreover, according to the Figures $\mathrm{B}$ of the nitrates reduction, we have noted a reduction peak at $-0.3 \mathrm{~V} / \mathrm{SCE}$ for the four cathodes tested, which corresponds to the reduction of nitrates at different scan rates. ${ }^{34}$ Hence, the scan rate has an influence on the current intensity. So, at higher scan rate, the reduction peak is so intense. However, at a scanning speed of $100 \mathrm{mV} / \mathrm{s}$, we noticed a moderate oxidation peaks at $-1.0 \mathrm{~V} / \mathrm{SCE}$ and $0.7 \mathrm{~V} / \mathrm{SCE}$. At a scan rate of $50 \mathrm{mV} / \mathrm{s}$ the nitrate reduction peak is lower than the other higher speed, but at this scan rate we didn't noticed any undesirable peak. For this raison, we choose the $50 \mathrm{mV} / \mathrm{s}$ as the optimal scan rate.

According to the literatures, the electroreduction of nitrites ions on an electrode modified with polypyrrole nanowires was improved at high scan rate. So, with increasing of scan rate the reduction peak moved to negative values, the favorable scan rate studied by the authors was similarly with that found in our work, $\mathrm{V}=50 \mathrm{mV} / \mathrm{s}$, this suggests that the reduction process is controlled by diffusion process. ${ }^{35}$

In the other hand, the comparison between the selectivity of the zinc, copper, graphite and stainless steel electrodes revealed that copper cathode is the most efficient for the nitrites reduction. Concerning the nitrates reduction, the four electrodes tested showed a significant efficiency with different peak intensity. Thus, for the other optimization test, we selected the copper electrode for the nitrite and nitrate reductions.

\section{Effect of initial concentration}

The initial nitrites and nitrates concentrations effect on the peak intensity was realized on the electrochemical cell containing the contaminated solutions with nitrites and nitrates ions respectively at different concentrations (from $10 \mathrm{mg}^{-\mathrm{NO}_{\mathrm{x}}}{ }^{-} / \mathrm{L}$ to $300 \mathrm{mg}-\mathrm{NO}_{\mathrm{x}}^{-} / \mathrm{L}$ ), using copper as cathode at a scan rate of $50 \mathrm{mV} / \mathrm{s}$. The obtained voltammograms were superimposed and represented in Figure 4.

According to Fig. 4, the peak reduction intensity is proportional to the increase of the initial concentration. So, at high concentrations (200 and $300 \mathrm{mg}-\mathrm{NO}_{3}^{-} / \mathrm{L}$ ) the reduction peak is greater compared to the other tested concentrations.

The comparison between the different initial concentrations of nitrite and nitrate suggested that at very low concentrations the reduction peaks were disappeared. Indeed, the peak reduction intensity is proportional to the increase in the initial concentration, so, at high concentrations (200 and $300 \mathrm{mg} / \mathrm{L}$ ) the reduction peak is greater compared to the other tested concentrations. However, at very high concentrations of nitrites and nitrates, started from $200 \mathrm{mg} / \mathrm{L}$, an undesirable oxidation peak was appeared at $-0.8 \mathrm{~V} / \mathrm{SCE}$ in both obtained voltammograms. Therefore, the optimal concentration was chosen at $100 \mathrm{mg} / \mathrm{L}$ for both ions.

\section{Effect of $p H$}

$\mathrm{pH}$ optimizing allowed us to fix the favorable $\mathrm{pH}$ of the nitrite and nitrate reductions on copper with an optimized initial concentration at $100 \mathrm{mg} / \mathrm{L}$ and a scanning rate of $50 \mathrm{mV} / \mathrm{s}$. We have tested different $\mathrm{pH}$ values, the obtained voltammograms are presented in Fig. 5.

According to the Figs. 5A and 5C, we noticed that the very acid $\mathrm{pH}(\mathrm{pH}=3)$ strongly affects the reaction of the reduction of and leads to an unwanted oxidation reactions signified by the appearance of an oxidation peak at $-0.3 \mathrm{~V} / \mathrm{SCE}$ with a sharp drop in the current intensity because of the reduction of the hydrogen accompanied by a violent release of the gas $\mathrm{H}_{2}$. This current drop covered the other reduction reactions for the other tested pHs. For this reason, we have eliminated this $\mathrm{pH}$ value in the Figs. 5B and 5D for nitrite and nitrate respectively, in order to compare the voltammograms of the other $\mathrm{pHs}$. 

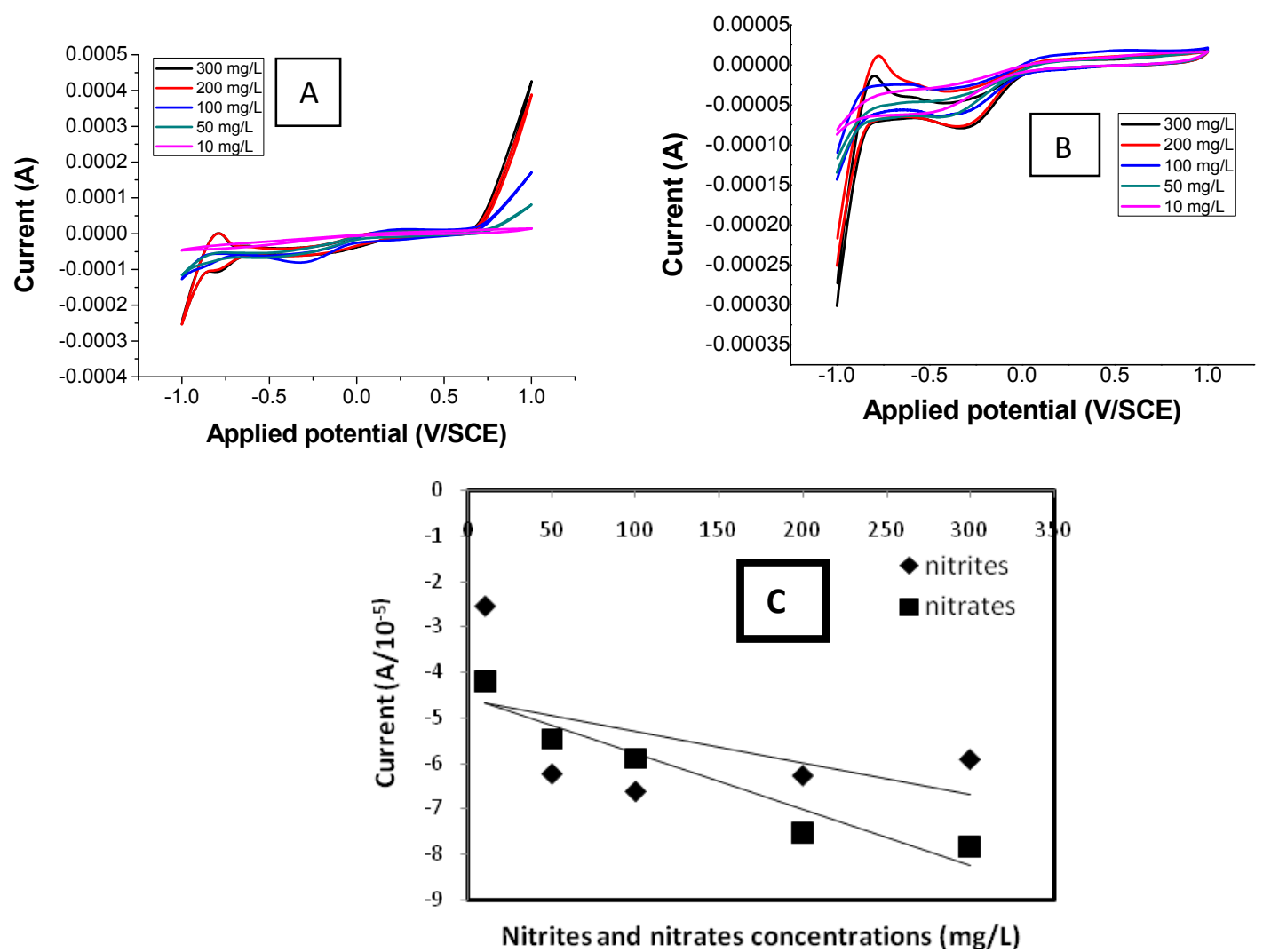

Fig. 4 - Voltammograms presented the initial concentration of nitrites (A) and nitrates (B) effects on the reduction peaks intensities, with a scan rate of $50 \mathrm{mV} / \mathrm{s}$. (C) relationship between current electroreduction and initial concentrations of nitrites and nitrates.
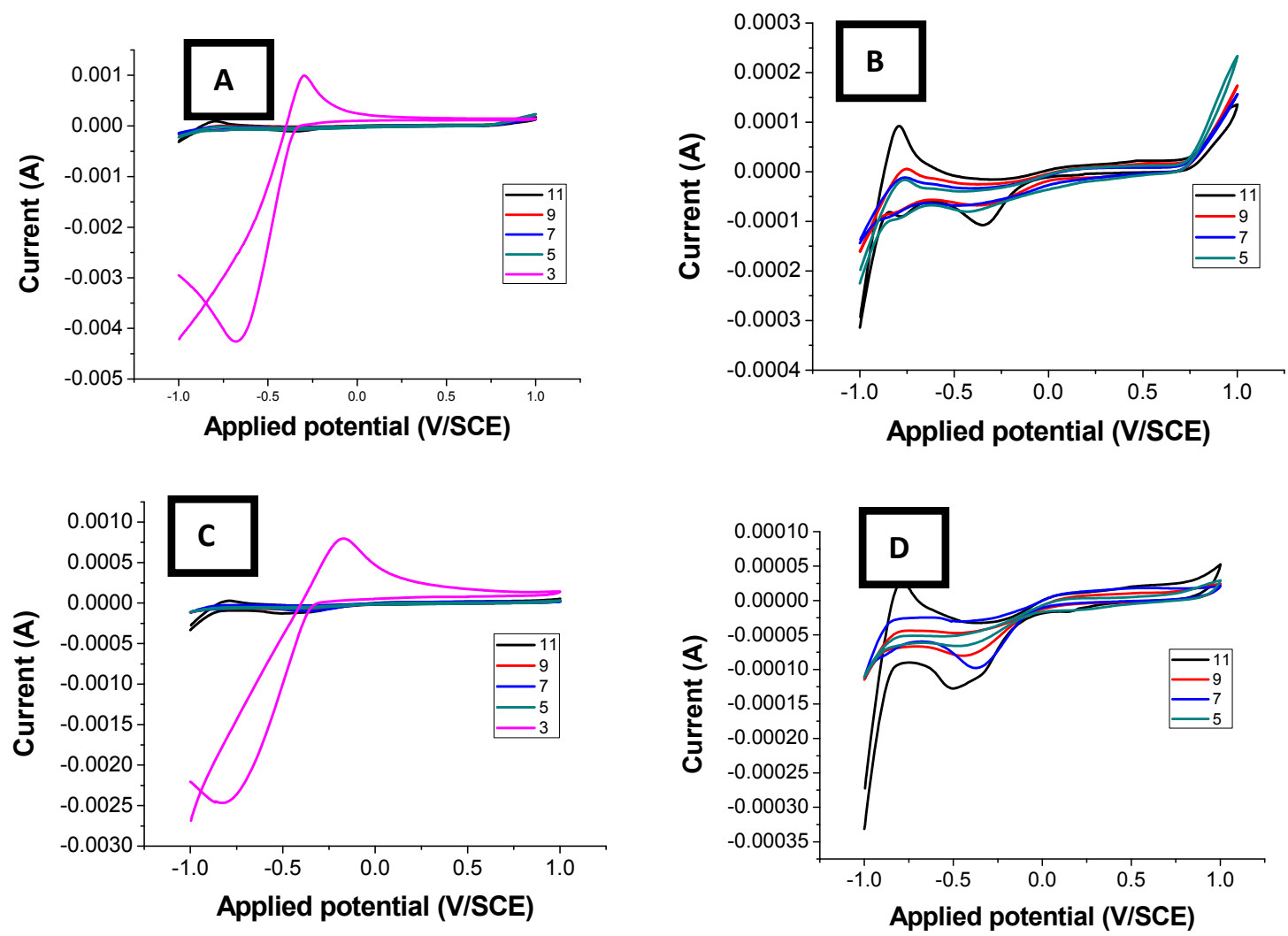

Fig. 5 - Voltamogrammes presented the $\mathrm{pH}$ effect on the reduction peaks of nitrites (A and B) and nitrates (C and D) with a scan rate of $50 \mathrm{mV} / \mathrm{s}$ and initial ammonium concentration of $100 \mathrm{mg} / \mathrm{L}$. 

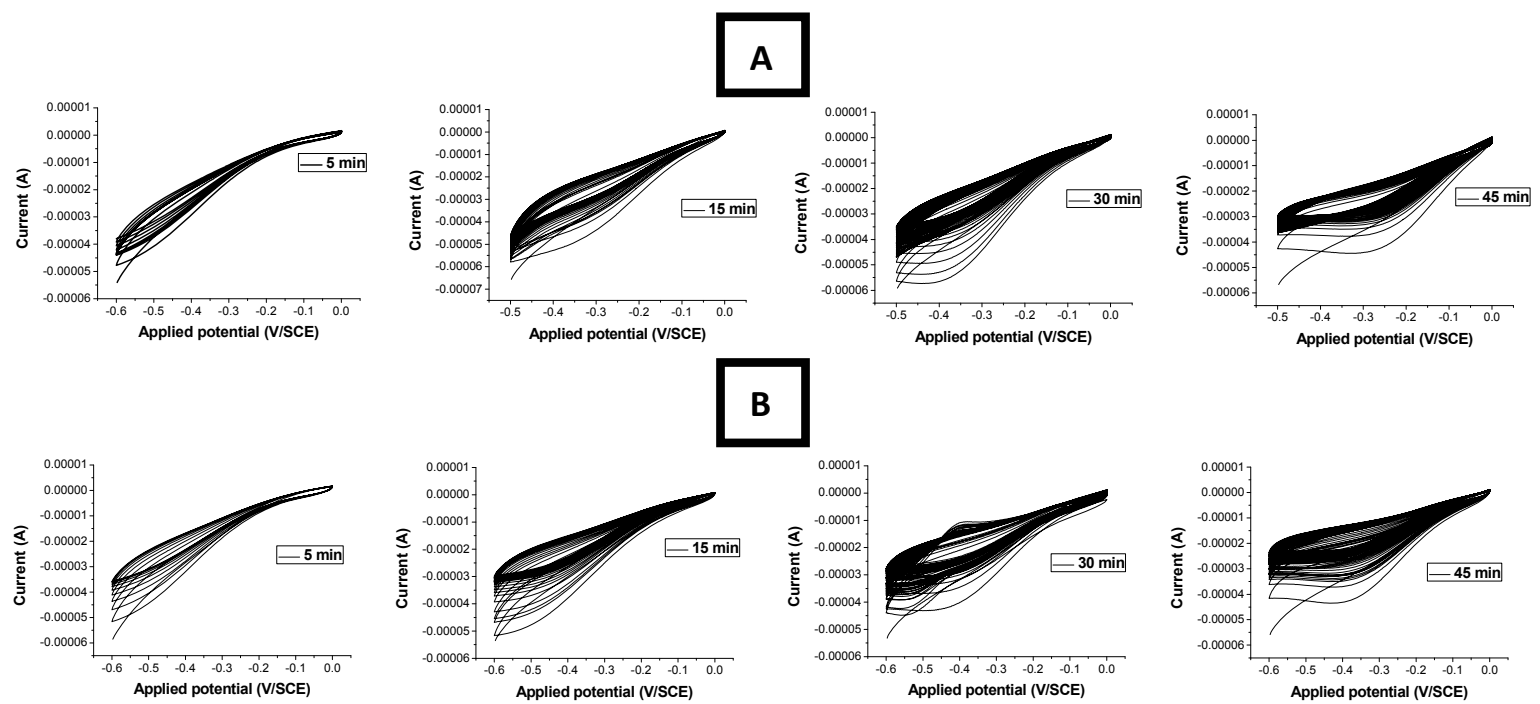

Fig. 6 - Voltamogrammes presented the contact time effect on the reduction peaks of nitrites (A) and nitrates (B) with a scan rate of $50 \mathrm{mV} / \mathrm{s}, \mathrm{pH}=7$ and initial ammonium concentration of $100 \mathrm{mg} / \mathrm{L}$.

Indeed, we have noticed that our reduction peaks are optimal at a $\mathrm{pH}=11$ accompanied by the appearance of unwanted oxidation peaks at $-0.8 \mathrm{~V} / \mathrm{SCE}$. At $\mathrm{pH}=7$ reduction peaks are less important compared to $\mathrm{pH}=11$ but at neutrality we did not notice any oxidation peak for both tested ions. For these reasons the optimal peak of reduction has been set at $\mathrm{pH}=7$.

According to the literatures, the $\mathrm{pH}$ affect also the formed species in the electrolytic medium and conduct to the appearance of unwanted by product such as NO that could form in alkaline solution form the reduction of nitrite ions $\mathrm{s}^{31,32}$ and in acidic solution using copper-containing nitrite reductase model complex incorporated into collagen film as electrode. $^{36}$ For the nitrates ions, in alkaline solution the reduction could produce ammonia as final product according to the following equations (12 and 13). ${ }^{37}$

$$
\begin{aligned}
& \mathrm{NO}_{3}^{-}+\mathrm{H}_{2} \mathrm{O}+2 \theta^{-} \rightarrow \mathrm{NO}_{2}^{-}+2 \mathrm{OH}^{-} \\
& \mathrm{NO}_{2}^{-}+5 \mathrm{H}_{2} \mathrm{O}+6 \theta^{-} \rightarrow \mathrm{NH}_{2}+7 \mathrm{H}_{2} \mathrm{O}
\end{aligned}
$$

In acidic solution, the nitrates reduction could produce different nitrogen gas according to the reduction potential, such as $\mathrm{N}_{2} \mathrm{O}$ and $\mathrm{N}_{2}$ at the potentials $\mathrm{E}<0.4 \mathrm{~V} / \mathrm{NHE}^{33}$

\section{Effect of contact time}

After optimization of the scan rate, the initial concentration and the $\mathrm{pH}$ of the electrolytic medium, we proceeded to the reduction of nitrite and nitrate by application of several cycles voltammetry during well-defined time intervals on a copper electrode. In addition, we defined the potential range at $-0.6 \mathrm{~V} / \mathrm{SCE}$ to $0.0 \mathrm{~V} / \mathrm{SCE}$ for the reduction of both ions. The results of the obtained voltammograms are presented in Fig. 6.

According to the voltammograms shown in Figure 6, we have noticed a decrease in peak reduction intensity as a function of time and of the cycle's number. Indeed, in the voltammograms of the nitrite reduction, the peak intensity decreased from $-0.0445 \mathrm{~mA}$ to a current value of $-0.0347 \mathrm{~mA}$ during 5 min of scanning (Fig. $6 \mathrm{~B} 1$ ). On the other hand, the peak intensity could reach a value of $0.0301 \mathrm{~mA}$ and $-0.0228 \mathrm{~mA}$ after the 30 th and $60^{\text {th }}$ potential scan cycles respectively. These values could reach a minimum value of- $0.0218 \mathrm{~mA}$ after the $100^{\text {th }}$ scan cycle. These results suggest that the concentration of nitrites decreased during sweeps and as a function of applied cycle numbers.

In addition, in the voltammograms of Fig. 7B of the nitrate reduction, the reduction peak intensity decreased from $-0.0486 \mathrm{~mA}$ to $-0.0335 \mathrm{~mA}$ after $5 \mathrm{~min}$ of scan. This value remained to decrease to $-0.0277 \mathrm{~mA}$ and to $-0.0207 \mathrm{~mA}$ after $15 \mathrm{~min}$ and $30 \mathrm{~min}$ which correspond to $30^{\text {th }}$ and $60^{\text {th }}$ cycles respectively. Thus, these values could reach a minimum value of $-0.0187 \mathrm{~mA}$ after the $100^{\text {th }}$ scan, which indicates that the concentration of nitrates decreased in the reaction medium during sweeps and as a function of the applied cycle's number.

Moreover, dosages of the residual concentrations of nitrites and nitrates respectively after each applied cycle have been effectuated, in order to confirm the results found by cyclic voltammetry. 


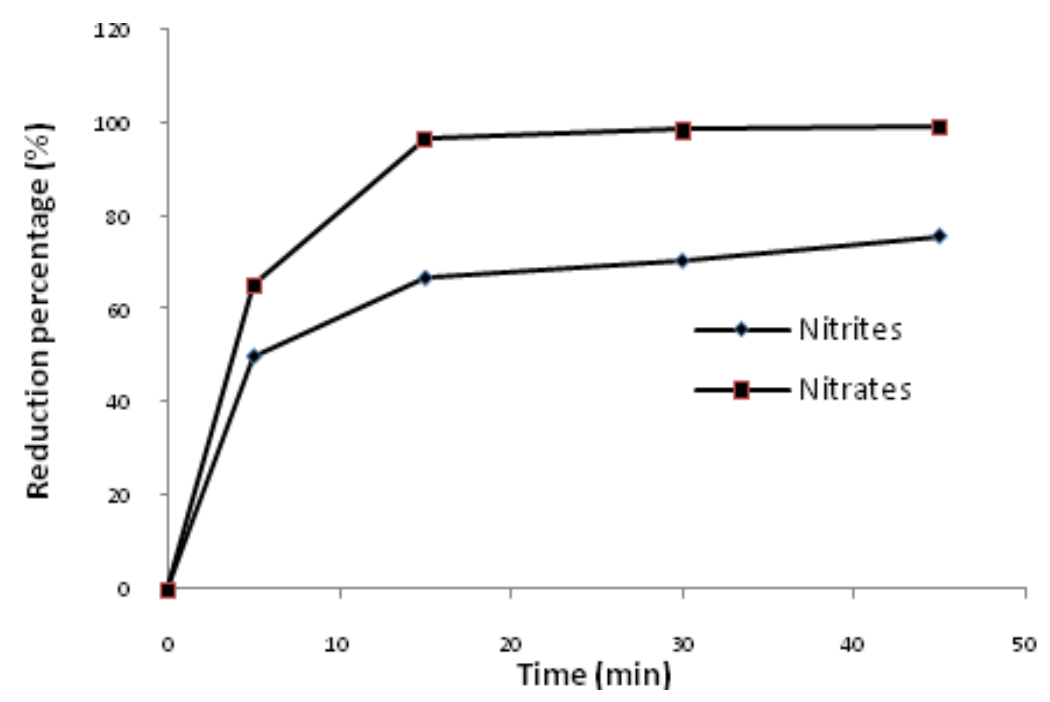

Fig. 7 - Reduction percentage of nitrites and nitrates as a function of time.

\section{Study of nitrites and nitrates electrochemical reduction on the copper cathode}

In order to confirm our interpretations, dosages of residual nitrite and nitrate after each voltammetric test were carried out. The results are exploited in the form of the trend curves and presented in Figure 7.

According to the Fig. 7 we noted that the increase in cyclic potential sweep number improved the rates of nitrite and nitrate reductions. At a scan of 10 cycles, about $50 \%$ and $65.33 \%$ of nitrite and nitrate respectively were reduced. Beyond the 30th cycle, the yield exceeded $70.4 \%$ until the elimination of $75.7 \%$ of nitrites and from $96.8 \%$ to about $99 \%$ for the nitrates at the 100th cycle sweep. These results suggest that under successive cyclical scans of potential, the yield of the reduction of our ions is important.

\section{CONCLUSIONS}

In this work, we treated nitrite and nitrate in aqueous solution by the electrochemical technique, comparing the performance of different electrode materials. On the most efficient electrode, which is copper, we optimized the various operating parameters of cyclic voltammetry, such as the scanning rate, the applied potential range, the $\mathrm{pH}$, the initial effluent concentration and the time. Indeed, the application of different scanning speeds allowed us to deduce the type of reaction and thus to select the optimal speed of the reduction of both ions for the different tested cathode materials. From the results obtained, we conclude that our reductions reactions are rapid and spontaneous. However, high scanning rates lead to undesirable intermediate reactions. Moreover, the optimization of the initial concentration of the contaminated solutions and $\mathrm{pH}$ allowed us to maintain them at $100 \mathrm{mg} / \mathrm{L}$ and 7 respectively. The effect of reduction contact time or the applied cycle number suggests that the increase in the cycle number improves nitrate and nitrite reduction rates which can reach $99 \%$ and $96.5 \%$ respectively in the 100 th cycle. Our treatment process has proven a remarkably effective in reduction of nitrite and nitrate, which can be applied in the water treatment rich in both contaminants.

Acknowledgements. This work was financed by University of M'Hamed Bougara of Boumerdes. We likewise greatly appreciate the help of SONATRACH for the provided analyses to this study. So, the constructive comments from Prof. Aliouch D., Dr. Khemili S., Dr. Belounes O. and Dr. Gana M. L. have helped us to improve this manuscript. The authors would like to thank also Dr IGHIL ALI M for its relevant remarks and its careful reading of this manuscript.

\section{REFERENCES}

1. N. Ziadi, B. Gagnon, A. Cambrouis, "Communication on colloque sur l'azote”, Québec, 2007.

2. J. N. Galloway, F. J. Dentener, D. G. Capone, E. W. Boyer, R. W. Howarth, S. P. Seitzinger, G. P. Asner, C. Cleveland, P. Green, E. A. Holland, D. M. Karl, A. Michaels, J. H. Porter, A. Townsend and C. J. Vöosmarty, Biogeochemistry, 2004, 70, 153-226.

3. M. Hirczak and A. Mollard, Rev. d'économie régionale \& urbaine, 2004, 5, 845-868. 
4. M. Benoît, J. P. Deffontaines, F. Gras, E. Bienaime and R. Riela-Cosserat, Cahiers agricultures, 1997, 6, 97-105.

5. D. H. K. Lee, Environ. Research, 1970, 3, 484-511.

6. T. Peng, C. Feng, W. Hu, N. Chen, Q. He, S. Dong, Y. Xu, and M. Li, Biochem. Engineer. J., 2018, 134, 12-21.

7. Z. Wang, S. He, J. Huang, and W. Chen, Environmental Pollution, 2018, 238, 562-572.

8. R.-C. Zhang, X.-J. Xu, C. Chen, D.-F. Xing, B. Shao, W-Z. Liu, A.-J. Wang, D.-J. Lee and N.-Q. Ren, Water Research, 2018, 143, 355-366.

9. F. Di Capua, F. Pirozzi, P. N. L. Lens and G. Esposito, Chem. Engineer. J., 2019, 362, 922-937.

10. S. Wen, K. Hu, Y. Chen and Y. Hu, J. Hazardous Mater., 2019, 373, 359-366.

11. C. Fan, P. Wang, W. Zhou, S. Wu, S. He, J. Huang and L. Cao, Sci. of The Total Environ., 2018, 643, 127-133.

12. A. Breytus, D. Hasson, R. Semiat and H. Shemer, Separation and Purification Technology, 2019, 226, 252258.

13. G. Mendow, C. I. Grosso, A. Sánchez and C. A. Querini, Chem. Engineer. Research and Design, 2017, 125, 348-360.

14. A. A. Hekmatzadeh, A. Karimi-Jashni, N. Talebbeydokhti and B. Kløve, Desalination, 2013, 326, 125-134.

15. H. Xu, Y. Li, M. Ding, W. Chen and C. Lu, Water Research, 2018, 143, 250-259.

16. K. Häyrynen, E. Pongrácz, V. Väisänen, N. Pap, M. Mänttäri, J. Langwaldt and R. Liisa Keiski, Desalination, 2009, 240, 280-289.

17. Z. Qi, S. You, N. Ren, Electrochim. Acta, 2017, 229, 96101.

18. J. Ding, W. Li, Q. L. Zhao, K. Wang, Z. Zheng and Y. Z. Gao, Chem. Engineer. J., 2015, 271, 252-259.

19. A. S. Koparal and Ü. B. Öğ̈̈tveren, J. Hazardous Mater., 2002, 89, 83-94.

20. A. B. Couto, S. S. Oishi and N. G. Ferreira, J. Ind. Engineer. Chem., 2016, 39, 210-217.

21. G. Pérez, R. Ibáñez, A. M. Urtiaga and I. Ortiz, Chem. Engineer. J., 2012, 197, 475-482.
22. M. Li, C. Feng, Z. Zhang, X. Lei, R. Chen, Y. Yang and N. Sugiura, J. Hazardous Mater., 2009, 171, 724-730.

23. G. Hopnyi and E. M. Rizmayer, J. Electroanal. Chem., 1985, 188, 265-272.

24. J. D. Genders, D. Hartsough and D. T. Hobbs, J. Appl. Electrochem., 1996, 26, 1-9.

25. H. L. Li, D. H. Robertson and J. Q. Chambers, J. Electrochem. Soc., 1988,135, 1154-1158.

26. H. L. Li and J. Q. Chambers, J. Appl. Electrochem., 1988, 18, 454-458.

27. B. M. B. Felisilda, L. Hamenu, J. H. Park, C. S. Yoon and J. M. Ko, Int. J. Latest Research In Engineer. and Techn., 2016, 02, 60-66.

28. M. Paidar, K. Bouzek and H. Bergmann, Chem. Engineer. J., 2002, 85, 99-109.

29. J. T.Matsushima, V. C. Fernandes, A. B. Couto, M. R. Baldan and N. G. Ferreira, Hindawi Publishing Corporation, Int. J. Electrochem., 2012, doi:10.1155/2012/213420, 2012.

30. A. C. A. De Vooys, R. A. Van Santen and J. A. R. Van Veen, J. Molec. Cat. A: Chem., 2000, 154, 203-215.

31. L. A. Estudillo-Wong, G. Santillan-Diaz, E. M. ArceEstrada, N. Alonso-Vante and A. Manzo-Robledo, Electrochim. Acta 2013, 88, 358-364.

32. Y. X. Chen, S. P. Chen, Q. S. Chen, Z. Y. Zhou and S. G. Sun, Electrochim. Acta, 2008, 53, 6938-6943.

33. K. Nishimura, K. Machida and M. Enyo, Electrochim. Acta, 1991, 36, 877-880.

34. A. Nezar, "Réduction électrochimique des ions nitrate et nitrite sur électrode de cuivre, en milieu neutre: Apport à la compréhension du mécanisme réactionnel", Phd thesis, Paris University, 2009.

35. Y. Tian, J. Wang, Z. Wang and S. Wang, Synthetic Metals., 2004, 143, 309-313.

36. N. Isoda, H. Yokoyama, M. Nojiri, S. Suzuki and K. Yamaguchi, Bioelectrochem., 2010, 77, 82-88.

37. S. Amertharaj, N. Mohamed and M. A. Hasnat, Electrochim. Acta, 2014, 136, 557-564. 
